\title{
Governamentalidade didático-filosófica como prática de governo dos alunos: a leitura de textos filosóficos em sala de aula
}

\author{
DIDACTIC-PHILOSOPHICAL GOVERNAMENTALITY AS A PRACTICE OF GOVERNING \\ STUDENTS: READING PHILOSOPHICAL TEXTS IN THE CLASSROOM
}

\author{
https://orcid.org/0000-0003-1386-955X Igor Corrêa de Barros ${ }^{A}$ \\ ${ }^{\text {A }}$ Universidade Federal de São João del Rei (UFSJ), São João del Rei, MG, Brasil \\ Recebido em: 29 mar. 2020 | Aceito em: 8 jul. 2021 \\ Correspondência: Igor Corrêa Barros (igorcbarros21@gmail.com)
}

\begin{abstract}
Resumo
O presente artigo busca promover uma reflexão sobre a didática do ensino de filosofia a partir de um relato de experiência com o uso de textos filosóficos no ensino médio. Analisa-se a didática aplicada nessa experiência à luz do aparato teórico metodológico do filósofo Michel Foucault (1926 - 1984). Este trabalho é uma tentativa e um convite a utilização de conceitos foucaultianos, em especial "governo" e "governamentalidade" como ferramentas para repensar a relação entre aluno e professor. Pensar o processo educacional como forma de governo e autogoverno, ou seja, como condução das condutas, significa levar em conta as práticas, estratégias e objetivos pelos quais os indivíduos, em sua liberdade, tentam governar os outros e a si mesmos.
\end{abstract}

Palavras-chave: texto filosófico; Foucault; governamentalidade; governo.

\section{Abstract}

This article aims to promote a reflection on the didatic teaching of philosophy from an experience using philosophical texts in high school. It analyses the didactics applied in this experience encompassing the theoretical methodological apparatus of the philosopher Michel Foucault (1926 - 1984). This work is an attempt and an invitation to use Foucauldian concepts, especially "government" and "governmentality" as tools to rethink the relationship between student and teacher. Reflecting on the educational process as a form of government and self-government or as way to control behaviors, means taking into consideration practices, strategies and objectives by which individuals, in their freedom, try to govern others and themselves.

Keywords: philosophical text; Foucault; governmentality; government. 


\section{Considerações Iniciais}

O objetivo deste artigo é investigar as dificuldades em se utilizar texto filosófico no ensino médio. Para isso, analisaremos os resultados do projeto de ensino Totalitarismo e Direitos Humanos, aplicado na Escola Estadual Cônego Osvaldo Lustosa, na cidade de São João Del-Rei, no segundo bimestre letivo de 2019, durante o programa Residência Pedagógica.

Analisaremos a experiência aqui relatada a partir do aparato teórico-metodológico presente no trabalho de Foucault em sua chamada fase ética (1980 - 1984). Este trabalho é uma tentativa e um convite à utilização de conceitos foucaultianos, em especial "governo" e "governamentalidade", como ferramentas para repensar a relação entre aluno e professor. Vale ressaltar que a prática docente nunca foi objeto de investigação do filósofo francês. O que se realiza no presente texto é uma análise da contribuição e dos limites dos conceitos foucaultianos para a reflexão da prática docente, em especial as noções governo e governamentalidade.

Utilizaremos o conceito ético-político de governamentalidade para refletirmos sobre as formas de se trabalhar textos filosóficos em sala de aula e também sobre outros aspectos da vida acadêmica. Nesse sentido, analiso a experiência aqui relatada como uma estratégia didático-filosófica de governo, isto é, como forma de conduzir e mediar o primeiro contato dos alunos com os textos filosóficos. Vale lembrar que governar possui, para Foucault, um sentido ético-político e está ligado à forma como os indivíduos conduzem os outros e a si mesmos.

Este artigo está divido em quatro partes. Este trabalho tratará inicialmente de apresentar o conceito de governamentalidade e a forma que o indivíduo, em sua liberdade, procura conduzir os outros e a si mesmo. Em seguida, será relatada minha experiência com o uso de textos filosóficos em um projeto de ensino aplicado em uma turma de terceiro ano do ensino médio. Em um terceiro momento, o foco recairá sobre a análise da didática empregada na experiência relatada como uma forma de governo-governamentalidade didático-filosófica. Por fim, será feita uma análise de como os conceitos governamentalidade e cuidado de si, presentes na ética foucaultiana, podem ajudar na reflexão sobre a prática docente.

\section{Genealogia da governamentalidade}

Foucault (2014) sustenta que na sociedade capitalista o poder não é exercido somente por meio da violência e da censura, ou, pelo menos, que a repressão não é o essencial nas relações de poder. O poder não anula e exclui o indivíduo, mas atua por meio da produção e da fabricação de verdades, discursos e do próprio sujeito. Segundo Foucault (2002), o poder 
transita pelo indivíduo que ele produz, adestrando e controlando seus corpos no interior das instituições panópticas e regulando os fenômenos biológicos da população por meio de dispositivos estatais. A disciplina do corpo humano e biopolítica da população, a junção entre um poder normalizador e um poder regulador, constitui um elemento chave para entender os dispositivos que sustentam a governamentalidade moderna, isto é, a condução do sujeito e da população.

O espaço aberto pela noção de biopolítica atribuiu novos contornos à analítica do poder. Ao investigar os dispositivos de poder ligados à condução da vida da população, Foucault voltou sua atenção para fenômenos de maior escala, o que marcou a expansão de seus estudos sobre o poder. No curso Segurança, território, população (1977-1978), o escopo consistia em realizar uma análise histórica das práticas e mecanismos que se articularam para a formação das tecnologias governamentais modernas. Foucault introduz o conceito de governamentalidade para auxiliar sua investigação genealógica desses dispositivos de gerenciamento da população. Nas palavras do autor, governamentalidade refere-se ao:

conjunto constituído pelas instituições, os procedimentos, análises e reflexões, os cálculos e as táticas que permitem exercer essa forma bem específica, embora muito complexa, de poder que tem por alvo principal a população, por principal forma de saber a economia política e por instrumento técnico essencial os dispositivos de segurança. (FOUCAULT, 2008, p 143-144).

Por governamentalidade, Foucault (2008) entende o conjunto de instituições, procedimentos, dispositivos, reflexões e programas governamentais que tornaram possível o exercício de um tipo específico de poder centrado na administração da população. A história da governamentalidade é um estudo das práticas de governo realizada em duas dimensões: uma tecnológica, na qual o governo é observado como tecnologia, segundo o "conjunto de pessoas, técnicas, instituições e instrumentos para a condução da conduta dos indivíduos" (MILLER, e ROSE, 2008, p. 16). Nesse momento Foucault apresenta, no curso de 1977- 1978, uma análise das tecnologias de segurança, da pastoral cristã e da razão de Estado. A outra dimensão, programática, diz respeito aos múltiplos programas de governo e às racionalidades governamentais. No curso de 1978- 1979, Nascimento da biopolítica, o estudo da governamentalidade se dirige ao liberalismo e ao neoliberalismo.

A tese central da história da governamentalidade é que a ideia de condução presente nas tecnologias individualizantes e totalizantes da pastoral cristã está na gênese das tecnologias modernas de governo dos homens. Foucault defende que a ideia de condução presente na 
relação pastor-ovelha não desapareceu com o fim do pastorado, mas foi modificada na modernidade. "Não houve passagem do pastorado religioso à outras formas de conduta. Houve, de fato, intensificação, multiplicação, proliferação geral dessa questão e de suas técnicas de conduta" (FOUCAULT, 2008, p. 309). O autor sustenta sua tese defendendo que ideias da pastoral, como salvação, verdade e confissão foram modificadas e reconfiguradas pelo Estado.

De fato, a análise da pastoral marca a entrada do problema do governo nos estudos foucaultianos. O poder pastoral é uma relação que tem por objetivo a incessante busca pela melhor forma de se conduzir e governar os discípulos. O problema da condução dos homens se proliferou na modernidade e penetrou o âmbito político, inserindo a busca pela melhor forma de se conduzir os indivíduos e a população, ou seja, a busca por uma racionalidade específica para governar não mais no âmbito privado, mas no âmbito político do governo dos homens. $\mathrm{O}$ problema do governo apresenta-se no século XVI das mais variadas maneiras: governo estatal; governo das crianças, representado pela pedagogia; governo das almas, tema central da pastoral cristã, entre outros.

O estudo sobre a governamentalidade e as formas de governo nos ajudam a entender porque Foucault foi, paulatinamente, substituindo o termo "poder" por "governo". A concepção de governo em Foucault está ligada à noção de conduta e ambos foram extraídos das análises da pastoral cristã. O termo conduta possui uma ambiguidade que abrange desde o ato de conduzir alguém ou um grupo, até a forma como o indivíduo conduz a si "O ponto de contato do modo como os indivíduos são manipulados e conhecidos por outros encontra-se ligado ao modo como se conduzem e se conhecem a si próprios. Pode chamar-se a isto o governo." (FOUCAULT, 1993, p. 201). A noção de conduta foi uma das bases para a elaboração do conceito de governamentalidade e para seu desdobramento na fase ética dos estudos foucaultianos.

Os estudos foucaultianos sobre a sexualidade dos gregos e romanos antigos levaram o autor a se interessar por essa visão da ética baseada no ascetismo e pautada nas práticas de si. Nas palavras de Foucault, "Não digo que a ética seja o cuidado de si, mas que, na Antiguidade, a ética como prática racional da liberdade girou em torno desse imperativo fundamental: 'cuidate de ti mesmo"” (FOUCAULT, 2006, p.268). Segundo Foucault (2006), na cultura grecoromana, a liberdade foi pensada como uma ética pautada no cuidado de si, que para nós pode significar uma forma de egoísmo, mas que, opostamente, durante a Antiguidade foi um princípio positivo. De acordo com o autor (2006), o terceiro momento do cuidado de si, o momento cristão, teria ocultado o momento socrático-platônico e o segundo momento 
helenístico-romano. Por isso, o autor busca apresentar o sentido do cuidado de si na cultura greco-romana. Assim, o tema do cuidado de si nasce em V A.C., chegando até o século IV D.C., e representa um fenômeno capital para a história da subjetividade e da verdade.

O cuidado de si representa uma ética em que o indivíduo se volta reflexivamente para si, elaborando novas formas de se governar, sempre visando alcançar liberdade e autonomia, esculpindo, assim, sua vida como uma "obra de arte". Digamos que, esquematicamente, no período chamado de Antiguidade o cuidado de si girou em torno de duas questões: como ter acesso à verdade e quais as práticas espirituais que permitiriam ao sujeito ter acesso à verdade. A "verdade" e o "cuidado de si" são duas temáticas que jamais estiveram separadas. Resumidamente, podemos definir o cuidado de si como o conjunto de práticas espirituais, o conjunto de exercícios e atividades que permitirão ao sujeito se transformar e, consequentemente, ter acesso à verdade. Naquela sociedade muitas eram as práticas direcionadas aos jovens de elite: regimes direcionados à comida, às bebidas, ao sono e ao sexo; exercícios físicos, exame de consciência, meditação, escrita, entre outros.

De acordo com Foucault (2006), essa busca pela autotransformação, isto é, esse preço a se pagar para ter acesso à verdade, possui três características: primeiro, a verdade jamais é dada ao sujeito como um simples ato de conhecimento. Para alcançar a verdade o sujeito precisa deslocar-se, modificar-se, tornar-se outro para então ser merecedor e alcançar a verdade. Não há verdade sem autotransformação do sujeito. Em segundo lugar, a espiritualidade postula que essa transformação do sujeito é um processo de conversão, um trabalho que o sujeito realiza sobre si mesmo. Transformação progressiva de si para consigo, um trabalho que só o sujeito pode realizar para, finalmente, ser merecedor da verdade. Por último, o acesso à verdade é o momento de ascensão do sujeito. Mais do que uma recompensa pelos atos de transformação de si, a verdade é o que ilumina o sujeito, trazendo sabedoria e tranquilidade à alma. Em suma, o cuidado de si foi para os antigos o modo pelo qual o sujeito se relacionava com a verdade e, consequentemente, consigo mesmo. Cuidar de si para ter acesso à verdade, eis a fórmula de uma ética pautada nas práticas de si.

Na última fase dos estudos de Foucault, o conceito de governamentalidade ganha um sentido ético e passa a abranger um campo maior e até mesmo mais abstrato. $\mathrm{O}$ autor utiliza-se do termo para referir-se à relação do indivíduo com os outros e consigo mesmo (cuidado de si):

nessa noção de governamentalidade, viso ao conjunto das práticas pelas quais é possível constituir, definir, organizar, instrumentalizar as estratégias que os indivíduos, em sua liberdade, podem ter uns em relação aos outros. São indivíduos 
livres que tentam controlar, determinar, delimitar a liberdade dos outros e, para fazêlo, dispõem de certos instrumentos para governar os outros. Isso se fundamenta então na liberdade, na relação de si consigo mesmo e na relação com o outro. (FOUCAULT, 2006, p. 286).

Nota-se, portanto, que a noção de governamentalidade é reconfigurada. Senellart (2008) observa que, a partir de 1980, o conceito de governamentalidade se desvincula da questão do Estado e da população "para se tornar coextensivo ao campo semântico do "governo"” (SENELLART, 2008). Em suma, governamentalidade passa a englobar dois eixos: no primeiro momento, refere-se aos dispositivos de sujeição e condução da população; e, num segundo momento, aos modos pelos quais os indivíduos buscam conduzir os outros (governo dos outros) e autoconduzir (governo de si).

Bem, se o conceito de governamentalidade se aplica a todos os níveis da sociedade, e a escola está inserida nesse âmbito, proponho a reflexão sobre a aplicação desse conceito no ambiente acadêmico, especificamente na relação professor-aluno. Em suma, defendemos que na escola o que se visa, assim como em outros níveis da sociedade, é uma condução das condutas. Partindo da noção de governamentalidade, acreditamos que o exercício da prática docente passa pela forma como o professor busca se conduzir e conduzir os alunos.

\section{A observação e a prática no ensino médio: o uso de textos filosóficos}

A experiência aqui relatada faz parte da minha atuação no programa Residência Pedagógica, quando discente do curso de licenciatura em Filosofia na Universidade Federal de São João Del Rei - UFSJ. Atuei na Escola Estadual Cônego Osvaldo Lustosa, município de São João Del-Rei, entre agosto de 2018 e janeiro de 2020. Foram 440 horas divididas em 3 etapas: imersão ou ambientação, regência e atividades extraclasse. Detenho-me, aqui à segunda etapa, ocorrida entre maio e julho de 2019.

O projeto de ensino Totalitarismo e Direitos Humanos foi desenvolvido em uma turma de terceiro ano e teve por objetivo trabalhar com os alunos os aspectos constitutivos dos regimes totalitários, destacando a importância da atividade política como forma de construção de uma sociedade mais democrática e justa. O projeto teve início no dia 9 de maio e foi concluído no dia 4 de julho de 2019, totalizando oito aulas ao longo do segundo bimestre. Como são muitos os regimes totalitários, focamos no Nazismo. Para destrinchar o assunto, utilizamos ao longo 
do projeto trechos de dois textos filosóficos: Cotidiano e História, de Agnes Heller (ver anexo I), e Vigiar e Punir, de Foucault (ver anexo II).

Na primeira aula do projeto foi realizada uma dinâmica de introdução ao contexto histórico da segunda guerra mundial e das principais características do nazismo. Por já terem estudado o assunto na disciplina de história, os alunos demonstraram bastante conhecimento sobre a temática, o que facilitou o prosseguimento do projeto, uma vez que, sem uma boa base histórica sobre o período da segunda guerra e sobre a ascensão dos regimes totalitários, parte do projeto não poderia ter sido realizado.

Na segunda aula foi utilizado um trecho do livro $O$ cotidiano e a história. No fragmento a filósofa húngara enfatiza que o preconceito faz parte do pensamento e do comportamento cotidiano, e que muitas vezes é utilizado pelas classes dominantes com objetivo de manter a coesão de uma estrutura social que lhes beneficie. No texto, Heller cita o regime nazista de Adolf Hitler como exemplo de uma sociedade na qual as pessoas são manipuladas através de sistemas de poder baseado na disseminação de preconceitos. O objetivo de trabalhar o texto foi refletir e problematizar os preconceitos como parte de uma teia de relações de poder na qual uma determinada classe procura dominar a outra. $\mathrm{O}$ texto serviu como ponto de apoio para refletir sobre como o Nazismo incentivou a perseguição contra os judeus e outras minorias em nome de uma ideologia supremacista. Assim, estava colocada a necessidade de se questionar como somos manipulados ao reproduzir os preconceitos e interiorizar a norma social.

Na quarta e na quinta aula, trabalhamos um trecho do livro Vigiar e Punir, de Michel Foucault, que diz respeito à normalização dos indivíduos por meio da disciplina. A partir do conceito de sociedade disciplinar é possível pensar o totalitarismo como uma forma de dominação política exercida por mecanismos de poder que visam a normalização do corpo e a regulação da população. $\mathrm{O}$ fragmento (aproximadamente uma página e meia de texto) remete à parte em que Foucault explica o conceito de disciplina e o uso de alguns métodos disciplinares, como arte das distribuições (controle do espaço), controle das atividades (controle do tempo) e vigilância. Por conter conceitos novos para os alunos, como corpos dóceis, disciplina, anátomopolítica, entre outros, o texto foi trabalhado com apoio do recurso de PowerPoint para auxiliar na leitura e explicação do texto.

No final do trabalho com cada texto os alunos entregaram uma atividade contendo algumas perguntas, entre elas: "Na sua opinião, o texto acima é de fácil compreensão? Justifique sua resposta". A partir do retorno dos alunos, avaliamos o resultado do trabalho com os textos 
filosóficos e procuramos investigar modos e metodologias possíveis de trabalhá-los em sala de aula.

Quando abordamos o primeiro texto ("Sobre o uso dos preconceitos", de $O$ Cotidiano $e$ a História), os alunos foram mais participativos e a discussão cumpriu melhor os objetivos estipulados, principalmente ao relacionar o texto com o Holocausto, um dos acontecimentos históricos que mais mobiliza a atenção das pessoas. A questão dos direitos das minorias é uma discussão que ganhou fôlego nos últimos anos, tornando-se uma preocupação da comunidade mundial, e por isso acredito que esses alunos já estejam envolvidos em algum grau nessa discussão. Ainda assim, os alunos demonstraram certa resistência em expressar suas opiniões. Acredito que seja mais do que vergonha ou apatia, mas, sim, uma acomodação, fruto da postura passiva que lhes é atribuída pela educação tradicional. Ao suscitar esse tipo de participação em sala de aula, a filosofia precisa lidar com o aluno que não está acostumado a uma postura ativa no processo educacional e despertar nele o apetite para o saber filosófico.

Outro ponto que gerou dificuldades foi a falta de compromisso de uma parcela de alunos em relação às atividades para casa. No caso do primeiro texto, dos 35 alunos da turma, apenas 21 entregaram a atividade acima mencionada. Acredito que o problema não seja exclusivo da filosofia, mas que a falta de valorização da disciplina corrobora para maior desinteresse por parte dos estudantes. Desses 21 alunos, 20 acharam o texto fácil e 1 o achou difícil. Em termos de porcentagem, levando em conta somente os alunos que entregaram a atividade, podemos concluir que $95 \%$ deles acharam o texto fácil e 4,8\% acharam o texto médio. Entre os alunos que acharam o texto fácil, a maioria justifica que o texto tem linguagem de fácil entendimento e que trata de temas do cotidiano.

O segundo texto ("Disciplina", de Vigiar e punir) também foi bem recebido pelos alunos. A leitura foi feita em conjunto, havendo pausas para explicar o conteúdo. Apesar dos novos conceitos presentes no texto, os alunos participaram e demonstraram interesse pelo assunto. A atividade que fizeram no final da quarta aula revelou que os estudantes tiveram entendimento satisfatório do conteúdo, já que foram capazes de descrever como a escola aplica os métodos disciplinares apresentados no texto.

O número de alunos que entregou a atividade solicitada foi ainda menor (17, do total de 35 alunos). Entre eles, 11 consideraram o texto fácil, 1 o considerou mais ou menos fácil ou mais ou menos difícil, 2 o consideraram difícil e 3 não souberam responder. Em porcentagem, $64,70 \%$ acharam o texto fácil; $5,88 \%$ acharam o texto médio; $11,76 \%$ acharam o texto difícil e $17,64 \%$ responderam incorretamente à pergunta. Entre os alunos que acharam o texto fácil foi 
recorrente a justificativa de que o texto tratava de temas cotidianos e que o vocabulário era acessível, mas houve ressalvas. Estas revelaram que, mesmo entre alunos que consideraram o texto fácil, houve maior dificuldade com o vocabulário. Os alunos que consideraram o texto difícil citaram o mesmo problema.

É consenso que escrita e leitura são aspectos importantes para a atividade filosófica e que o ensino de filosofia deve utilizar, de alguma forma, os clássicos filosóficos. A divergência entre os estudiosos está no modo como o texto filosófico será tratado em sala de aula com os estudantes, o que levanta alguns problemas como os critérios de escolha do texto, o modo de lidar com as dificuldades características desse tipo de leitura e a metodologia para uso do texto em sala.

No próximo tópico apresentaremos possíveis respostas para essas perguntas, utilizando o conceito de governamentalidade em Foucault para se pensar a mediação realizada em sala de aula como forma de condução da conduta com objetivo didático-filosófico. O projeto aqui apresentado, mesmo que de pequenas proporções, será utilizado como um ponto de reflexão e exemplo da utilização das noções de governamentalidade e cuidado de si na educação.

\section{Didática como forma de governamentalidade}

A Filosofia no Brasil enfrenta uma situação desafiadora. Após a reforma do ensino médio realizada em 2017 (Lei n. 13.415/2017), a Filosofia passa a ser ligada a apenas um dos itinerários formativos estabelecidos no texto da lei. Apesar do espaço conquistado nos últimos anos, o êxito da filosofia nesse novo cenário depende muito da didática aplicada pelo professor em sala de aula. "O desafio do professor de filosofia no Brasil hoje, assim, consiste em inventar uma prática de modo que o aprendizado de filosofia faça sentido para os jovens estudantes" (GALLO, 2009, p. 11).

A massificação do ensino criou uma nova realidade: a necessidade de se criar mediações pedagógicas com objetivo de superar problemas como a apatia e a evasão escolar. Nesse horizonte, o principal objetivo da didática filosófica deve ser encurtar a distância que pode existir entre a escola e a filosofia. Dessa forma, é consenso entre alguns estudiosos que a didática do ensino de filosofia deve ter como um de seus principais objetivos a articulação entre a tradição filosófica e o aluno. Partindo disso, ao se trabalhar textos filosóficos em sala, uma das preocupações refere-se à busca de uma prática que possa mediar o contato do aluno com o texto, oferecendo ferramentas necessárias para que o aluno possa se apropriar do conteúdo. 
O projeto aqui relatado foi aplicado em uma escola pública de São João Del-Rei, que exemplifica bem o processo de massificação. Dessa forma, minha atuação em sala de aula foi no sentido de conduzir a conduta dos alunos e oferecer ferramentas para tornar o texto filosófico mais acessível. Utilizando os conceitos do próprio Foucault, defendo que minha mediação foi uma forma de condução dos alunos com intenções didáticas - uma governamentalidade didático-filosófica.

Ao se falar em uma governamentalidade didático-filosófica, ou em governo dos alunos, precisamos enfatizar o papel do aluno nessa prática e prevenir mal entendidos. Por governamentalidade didático-filosófica entendo todas as práticas, as estratégias e todos os recursos utilizados na didática do ensino de Filosofia, cujo objetivo principal seja atribuir um papel ativo ao aluno no processo de ensino e superar a estrutura disciplinar e hierarquizadora da escola tradicional. Uma governamentalidade didático-filosófica busca romper com o papel de receptor de conteúdo que a escola há tanto tempo atribui ao aluno e com a postura de transmissor de conteúdo designada ao professor; é a busca incessante para garantir que o aluno se aproprie da Filosofia em seu processo de autoconstituição e desenvolva sua habilidade reflexiva. As práticas e as didáticas utilizadas nesse tipo de governamentalidade são as mais variadas possíveis; e dependem de cada professor, de cada escola e de cada realidade. No caso relatado neste texto, meu trabalho em sala de aula consistiu em criar uma mediação pedagógica que facilitasse o contato dos alunos com os textos e que ajudasse a construir uma autonomia reflexiva, de modo que o aluno pudesse se apropriar do conteúdo no âmbito ético-político de sua autoconstituição.

Nesse horizonte, o projeto relatado no tópico anterior servirá de ponto de apoio para uma reflexão sobre as possíveis formas de se trabalhar textos filosóficos em sala de aula. Analisaremos a didática utilizada no projeto e a relação entre professor e aluno como uma forma de governamentalidade escolar. Passemos aos critérios considerados na escolha dos textos e, depois, à metodologia aplicada no uso desses textos.

Os primeiros critérios considerados tanto na elaboração do projeto de ensino como na seleção dos textos que foram trabalhados referem-se ao pouco tempo destinado às aulas de filosofia no ensino médio e às relações e articulações possíveis entre assunto abordado, tema do texto e cotidiano dos alunos.

$\mathrm{Na}$ maioria das vezes, o primeiro contato do aluno com a filosofia acontece no ensino médio. Durante sua trajetória o aluno é ensinado a priorizar conteúdos que respondam à lógica de mercado, ou seja, que possam ajudar na sua formação profissional. Sendo considerada 
abstrata, o aluno não se sente minimamente tocado pela filosofia e não entende qual a importância dela na sua formação. Ao ter que despertar o interesse do aluno, há a necessidade de se trabalhar assuntos que sejam parte de seu cotidiano e que o façam perceber que a filosofia pode ajudá-lo a interpretar a realidade:

o interesse pela reflexão filosófica, assim como por qualquer outro assunto, só poderá ser despertado se os conteúdos se revelarem significativos para o sujeito da aprendizagem, quer dizer, além de serem objetivamente significativos, eles devem sêlo subjetivamente, inserindo-se num horizonte pessoal de experiências, conhecimento e valores. (RODRIGO, 2009, p. 38).

Rodrigo (2009) diz que uma forma de motivar o aluno para a reflexão filosófica é estabelecer uma relação entre o assunto a ser trabalhado e os conhecimentos que ele já possui, de modo que ele consiga relacionar a filosofia com seu cotidiano, suas referências culturais e suas vivências.

Outro critério refere-se à complexidade da linguagem filosófica e às dificuldades culturais e linguísticas apresentadas pelos alunos do ensino médio. Na conjuntura atual do ensino médio, a falta de gosto do aluno pelo ensino e as dificuldades de leitura e escrita são elementos que dificultam a utilização de textos filosóficos em sala de aula. Muitos alunos não são leitores assíduos e apresentam dificuldades de ler e interpretar textos simples. Sendo assim, os textos escolhidos devem "ser relativamente curtos, não apresentar dificuldades muito grandes do ponto de vista semântico e conceptual" (RODRIGO, 2009, p. 38). Conclui-se, portanto, que é preciso escolher textos que possam ser facilmente entendidos pelos alunos, que apresentem uma linguagem mais acessível à realidade do ensino médio.

A importância do texto filosófico possuir conteúdo significativo e uma linguagem acessível foi constatada no resultado da experiência desenvolvida. Dentre os alunos que acharam os textos fáceis, a maioria citou que os assuntos são parte do cotidiano deles e que os textos apresentaram vocabulário de fácil compreensão. Dessa forma, pode-se concluir que, para ser significativo, o saber filosófico precisa penetrar no universo do aluno de uma forma que possa ser compreendido sem maiores dificuldades.

Acreditamos que o aluno deve ter acesso ao texto filosófico e que ele tem capacidade para tal atividade, mas que ainda não possui as qualificações necessárias para ter acesso ao saber filosófico por conta própria. Essa capacidade autônoma de reflexão não é dada ao homem a priori, mas construída gradativamente. Dessa forma, acreditamos que o papel do professor é mediar e conduzir o aluno, sendo um facilitador nesse processo de aprendizagem, "de modo 
que o estudante conquiste progressivamente uma autonomia intelectual que o capacite a apropriar-se do conteúdo por conta própria” (RODRIGO, 2009, p. 38).

De acordo com Severino (2006), a leitura dos clássicos filosóficos necessita da utilização de certas orientações, métodos e sistematizações. Nesse sentido, o primeiro passo que utilizei em sala como mediador foi contextualizar o texto filosoficamente e historicamente, familiarizando o aluno com o autor e a temática. Ressalta Severino (2006): "Um texto não pode ser abordado fora de seu contexto, fora das circunstâncias constituídas pelas malhas históricoculturais que entrelaçam sentidos que foram sendo produzidos, amealhados e articulados ao longo do tempo histórico" (SEVERINO, 2006, p. 76).

Realizada a contextualização com os devidos cuidados, foi iniciada a leitura do texto escolhido. A leitura filosófica, segundo Severino (2006), é um “exercício de paciência”, porque o texto filosófico não se esgota numa primeira vez. O texto deve ser retomado, analisado de forma refinada, identificando os termos desconhecidos e suprindo as possíveis dúvidas que apareçam ao longo da leitura. Dessa forma, os textos foram lidos em grupo, em voz alta, de forma dialogada, buscando facilitar a compreensão dos alunos. No final de cada parágrafo, eram feitas pausas, tanto para a explicação das dúvidas, quanto para um debate sobre os temas.

Ferrari (2003) sustenta que a leitura dialogada é uma ferramenta didática que atribui maior liberdade e protagonismo ao aluno. Segundo o autor, o diálogo é uma maneira de olhar para o aluno de outra forma e criar uma relação entre aluno e professor que possibilite a "recuperação da liberdade e autonomia dos alunos, buscando, através do diálogo, uma nova prática pedagógica e uma nova relação entre professores-alunos-saber-poder" (FERRARI, 2003, p. 14). Dessa forma, a importância de se fazer uma leitura dialogada consiste em mediar a aproximação do aluno com o texto, ajudando-o a identificar nele algumas características que são próprias de um texto argumentativo, como o tema apresentado, o problema e a tese defendida pelo autor.

Assim, realizei em sala de aula uma condução da conduta dos alunos ou, em termos foucaultianos, um governo dos alunos com o objetivo de mediar o contato desses estudantes com o texto filosófico. Práticas didáticas como a leitura dialogada, a contextualização do conteúdo e a escolha de assuntos que façam parte do cotidiano dos alunos são algumas ferramentas que podem auxiliar na compreensão do texto filosófico e possibilitar que os estudantes, a partir dessa iniciação, possam utilizar esse aprendizado em seu processo de autoconstituição. Pensar a educação como uma governamentalidade significa, portanto, 
olhando sob a ótica do professor, buscar ferramentas para que os alunos possam lutar contra o excesso de governo dos outros e pela prevalência da condução de si próprio.

No próximo tópico, faremos um breve levantamento de alguns autores que tem utilizado conceitos da ética foucaultiana para refletir sobre o ambiente escolar. O objetivo é procurar mostrar como essas noções são utilizadas e de que modo podem auxiliar na reflexão a respeito da educação.

\section{Aproximações entre os estudos foucaultianos e a prática docente}

Penso que um dos maiores desafios do ensino atual seja repensar a relação professoraluno e elaborar métodos que possam superar a hierarquização e o autoritarismo de uma educação baseada no disciplinamento (BELTRÃO, 2000). Como uma instituição disciplinar, o modelo de escola vigente tem como objetivo criar sujeitos civilizados e facilitar a condução das populações, em consonância com a ordem social vigente, a fim de facilitar a governamentalidade. Como consequência, a escola produz sujeitos dóceis e suscetíveis a modulação, criando aptidões, capacidades e desejos. (FOUCAULT, 2014). Nota-se, portanto, que a escola produz em excesso de governo dos outros e faz com que os indivíduos criem para si uma ética de existência alinhada ao projeto social - o neoliberalismo.

Em suas análises da ética antiga, Foucault nos oferece conceitos que nos auxiliam na problematização dessa via de mão dupla que é a relação professor-aluno. Alguns autores têm refletido sobre a prática docente como uma experiência ética em termos foucaultianos - uma autoelaboração ética, isto é, uma forma de cuidar de si e do outro (FAVACHO, 2019; GALLO, 2006). Para Gallo (2006, p. 186) “o exercício do cuidado do outro, pela educação, pode redundar num cuidado de si, como um reflexo". Assim, o autor evidencia que a função do educador seria cuidar dos outros e, consequentemente, constituir-se como sujeito ético da ação pedagógica. Pensar a educação como um processo de condução de si e dos outros significa buscar formas e meios pelos quais professores e alunos possam se autoconstruir como sujeitos livres e autônomos. Dessa forma, a problematização do ensino sob a ótica do cuidado de si deve levar em conta o cuidado que o professor estabelece com o aluno e consigo mesmo.

A ação docente concebida como uma governamentalidade de si e dos outros significa pensar práticas e modos de ensino que possam superar o modelo de educação impulsionado pelas políticas governamentais. Pensar a docência como uma prática ética e política pressupõe novas formas de vivenciar a relação professor aluno e experimentar a si próprio como sujeito ativo da ação pedagógica. Para Pagni (2011), o maior desafio seria pensar o cuidado de si em 
meio às práticas de sujeição da educação atual. Todos esses autores citados anteriormente acreditam que o cuidado de si como prática pedagógica possui um potencial transformador e pode servir como ponto de apoio para repensar a relação entre educador e educando.

Por meio do cuidado de si, o educador pode se constituir como sujeito ético que experimenta novas formas de vivenciar a educação e de superar o papel tradicional de transmissor de conhecimento que lhe é atribuído. Segundo Dalbasco (2010), o cuidado de si pode ampliar o sentido da ação do educador “concebendo-o como alguém que 'estende a mão', que 'faz sair de si' e o 'conduz para fora"' (DALBOSCO, 2010, p. 102). O docente que busca novas formas de conduzir a docência e de experimentar a si próprio inclui moralmente o outro (DALBOSCO, 2010).

Uma das formas do docente "conduzir a educação para fora” é entender, como defende Paulo Freire, que educar "não é transferir conhecimento, mas criar as possibilidades para a sua própria produção ou a construção" (FREIRE, 2010, p. 47). A criação e a ressignificação do conhecimento exigem, por parte do professor, uma relação consigo mesmo, uma relação de crítica e engajamento social. Faz-se necessário que gestores e professores voltem sua atenção para as vivências extraescolares dos alunos, para suas interações sociais e culturais na comunidade em que estão inseridos. Resumidamente, um professor somente conseguirá que seu aluno se torne um sujeito esclarecido, autônomo, capaz de fazer uso do próprio entendimento se o mesmo assim o for. Sendo assim, deve-se pensar esse processo didático como uma atividade do professor e do aluno sob a condução do professor, na qual o professor engajado procura, por meio de sua autonomia, potenciar a autonomia dos alunos.

Metodologias e didáticas como a mediação e o diálogo, abordadas no tópico anterior, são apenas alguns modos pelos quais os docentes podem experimentar novas formas de vivenciar a educação. $\mathrm{O}$ cuidado de si no campo acadêmico pode acontecer das mais variadas formas. Dentro das escolas, profissionais engajados adotam modos de ensino que revelam maior liberdade do docente em relação ao que lhe é imposto pelo Estado como sua obrigação. Muitos são os projetos e aulas no sentido de contornar as dificuldades apresentadas na educação básica. Dificuldades essas que, muitas vezes, são negligenciadas pelo Estado, como falta de recursos, evasão escolar, desigualdade social e apatia dos alunos.

Cada escola produzirá aptidões e subjetividades de acordo com o modo de condução adotado por cada educador. A grande tarefa de nosso tempo é encontrar esses novos modos de existência, questiona Deleuze (1992, p. 132), “onde será que aparecem os germes de um novo modo de existência, comunitário ou individual, e em mim, será que existem tais germes?”. 
Houve "uma experiência grega, experiências cristãs, etc., mas não são os gregos nem os cristãos que farão a experiência por nós hoje" (DELEUZE, 1992, p. 132). A análise que Foucault nos oferece é apenas um ponto de partida para que nós, no interior da nossa luta, possamos buscar modos de vivenciar a prática educacional e a existência como um todo.

\section{Considerações finais}

Diminuir o nível do ensino para contornar os problemas decorrentes da massificação do mesmo vai na contramão do que acreditamos ser uma efetiva democratização do ensino: há que se conduzir o aluno para que ele, no contexto de suas experiências e de seus saberes, possa se apropriar do saber filosófico. Daí a necessidade de se discutir didáticas do ensino de filosofia, modos e práticas pelas quais o professor deve conduzir a conduta dos alunos. Somente assim o aluno será incluído ativamente no processo educacional- uma inclusão moral.

Pensar a educação como um processo de governamentalidade significa abordá-la como um exercício ético-político de condução dos outros e de si mesmo. Esse exercício envolve as diversas práticas e os objetivos pelos quais o professor irá conduzir o aluno em sala de aula e a didática que ele escolherá. Acredito que, mais do que estruturar o campo de ação do aluno e fazer com que ele atinja metas e assimile conteúdos de forma passiva, uma governamentalidade escolar deve estar pautada em fazer com que o aluno possa se autogovernar, apropriando-se do conteúdo trabalhado em sala.

O que chamei de governamentalidade didático-filosófica foi a didática empregada na condução de um projeto específico, voltada para a mediação entre aluno e texto filosófico. A experiência aqui abordada atesta a necessidade de uma didática que possa fazer uma mediação entre a teoria filosófica e o estudante de ensino médio. No final do projeto que apliquei, as respostas dos alunos demonstram que eles, em sua grande maioria, conseguiram compreender os textos sem maiores dificuldades. Mesmo que minha pesquisa se mostre de pequenas proporções, pois não apliquei um formulário mais elaborado para coletar os dados, pode-se concluir que os alunos sentem a necessidade de estudar assuntos que se apliquem ao seu cotidiano. Nesse sentido, esse é um viés pelo qual a filosofia pode encurtar sua distância em relação à escola e ao aluno.

Por fim, tomando como objeto de estudo o resultado da pesquisa de opinião que apliquei, acredito que através da leitura dialogada tenha sido possível despertar nos alunos o sentimento de pertencimento em relação à filosofia, afastando a ideia de que ela seja uma disciplina abstrata e inacessível, da qual eles não teriam capacidade de entender. Os alunos têm 
sim capacidade para estudar filosofia e devem fazê-lo, e seu sucesso dependerá das mediações pedagógicas adotadas por cada docente.

\section{Anexo I}

Primeiro texto trabalhado no projeto Totalitarismo e direitos humanos: $O$ cotidiano e $a$

\section{História.}

O preconceito é a categoria do pensamento e do comportamento cotidianos. Os preconceitos sempre desempenharam uma função importante também em esferas que, por sua universalidade, encontram-se acima da cotidianidade; mas não procedem essencialmente dessas esferas. Quem não se liberta de seus preconceitos: artísticos, científicos e políticos acaba fracassando, inclusive pessoalmente.

A maioria dos preconceitos, embora nem todos, são produtos das classes dominantes, mesmo quando essas pretendem, na esfera do para-si, contar com uma imagem do mundo relativamente isenta de preconceitos. O fundamento dessa situação é evidente: as classes dominantes desejam manter a coesão de uma estrutura social que lhes beneficia, em nome de um projeto de poder. Com ajuda dos preconceitos, apelam à particularidade individual, que, em função de seu conservadorismo de seu comodismo e de seu conformismo, ou também por causa de interesses imediatos — é de fácil mobilização contra os interesses de sua própria integração, desvinculando-se do seu sentido humano. $\mathrm{O}$ camponês húngaro que se lançou com entusiasmo na Primeira Guerra. Mundial, ou o operário alemão entregue de corpo e alma a Hitler, foram tipos humanos manipulados através de sistemas de preconceitos. Não é casual que fossem manipulados: seus interesses imediatos e individuais foram mobilizados contra seus princípios humanos, de modo que passaram a aceitar o que o poder dominante lhes impunha.

Deve-se observar ainda, neste contexto, que a classe burguesa, produz preconceitos em muito maior medida que todas "as classes sociais conhecidas até hoje". Isso não é apenas consequência de suas maiores possibilidades técnicas de dominação, mas também de seus esforços em universalizar sua ideologia.

A questão é esta: como libertarmos dos preconceitos? Há algum esquema, alguma receita, algum conselho que garanta essa libertação? Naturalmente que não. Em muitos casos, não somos capazes de perceber por que nossas ideias são preconceituosas, ou perceber que uma opinião era preconceito.

Podemos distinguir através do conteúdo muitos tipos de preconceito: preconceitos morais, científicos, políticos, preconceitos de grupo, nacionais, religiosos, raciais, etc. Qualquer que seja seu conteúdo, sua esfera é sempre a vida cotidiana e é sempre uma forma de julgamento e exclusão.

HELLER, Agnes. O Cotidiano e a História.4.ed. São Paulo: Paz e Terra, 1992. p. 43-60. 


\section{Anexo II}

Segundo texto trabalhado no projeto Totalitarismo e direitos humanos: Vigiar e Punir.

Houve, durante a época clássica, uma descoberta do corpo como objeto e alvo de poder. Não é a primeira vez, certamente, que o corpo é objeto de investimentos tão imperiosos e urgentes; em qualquer sociedade, o corpo está preso no interior de poderes muito apertados, que lhe impõem limitações, proibições ou obrigações. Muitas coisas, entretanto, são novas nessa descoberta. Não se trata de cuidar do corpo, em massa, grosso modo, como se fosse uma unidade indissociável, mas de trabalhá-lo detalhadamente; de exercer sobre ele uma coerção sem folga.

Os métodos que permitem o controle minucioso das operações do corpo, que realizam a sujeição constante de suas forças e lhes impõem uma relação de docilidade-utilidade, são o que podemos chamar as "disciplinas".

O momento histórico das disciplinas é o momento em que nasce uma arte do corpo humano, que visa não unicamente o aumento de suas habilidades, nem tampouco aprofundar sua sujeição, mas a formação de uma relação que no mesmo mecanismo o torna tanto mais obediente quanto é mais útil, e inversamente. Forma se então, uma política das coerções que são um trabalho sobre o corpo, uma manipulação calculada de seus elementos, de seus gestos, de seus comportamentos. O corpo humano entra numa maquinaria de poder que o esquadrinha, o desarticula e o recompõe. Uma "anatomia política", que é também igualmente uma "mecânica do poder", está nascendo; ela define como se pode ter domínio sobre o corpo dos outros, não simplesmente para que façam o que se quer, mas para que operem como se quer, com as técnicas, segundo a rapidez e a eficácia que se determina. A disciplina fabrica assim corpos submissos e exercitados, corpos "dóceis". A disciplina aumenta as forças do corpo (em termos econômicos de utilidade) e diminui essas mesmas forças (em termos políticos de obediência).

A disciplina procede em primeiro lugar à distribuição dos indivíduos no espaço (arte das distribuições). Lugares determinados se definem para satisfazer não só à necessidade de vigiar, de romper as comunicações perigosas, mas também de criar um espaço útil. As disciplinas, organizando as "celas", os "lugares" e as "fileiras" criam espaços complexos: ao mesmo tempo arquiteturais funcionais e hierárquicos. São espaços que realizam a fixação e permitem a circulação; recortam segmentos individuais e estabelecem ligações operatórias; garantem a obediência dos indivíduos, mas também uma melhor economia do tempo e dos gestos.

O tempo medido e pago deve ser também um tempo sem impureza nem defeito, um tempo de boa qualidade, e durante todo o seu transcurso o corpo deve ficar aplicado a seu exercício. A exatidão e a aplicação são, com a regularidade, as virtudes fundamentais do tempo disciplinar.

O exercício da disciplina supõe um dispositivo que obrigue pelo jogo do olhar; um aparelho onde as técnicas que permitem ver induzam a efeitos de poder, e onde, em troca, os meios de coerção tornem claramente visíveis aqueles sobre quem se aplicam. Ao lado da grande tecnologia dos óculos, das lentes, dos feixes luminosos, unida à fundação da física e da cosmologia novas, houve as pequenas técnicas das vigilâncias múltiplas e entrecruzadas, dos 
olhares que devem ver sem ser vistos; uma arte obscura da luz e do visível preparou em surdina um saber novo sobre o homem, através de técnicas para sujeitá-lo e processos para utilizá-lo.

A vigilância hierarquizada organiza funciona como um poder múltiplo, automático e anônimo; pois repousa sobre indivíduos, seu funcionamento é de uma rede de relações de alto a baixo, mas também até certo ponto de baixo para cima e lateralmente; essa rede 'sustenta' o conjunto, e o perpassa de efeitos de poder que se apoiam. O poder na vigilância hierarquizada das disciplinas não se detém como uma coisa, não se transfere como uma propriedade; funciona como uma máquina. O que permite ao poder disciplinar ser absolutamente indiscreto, pois está em toda parte e sempre alerta; e absolutamente "discreto", pois funciona permanentemente e em grande parte em silêncio.

O exame combina as técnicas da hierarquia que vigia e as da sanção que normaliza. É um controle normalizante, uma vigilância que permite qualificar, classificar e punir. Seu resultado é um arquivo inteiro com detalhes e minúcias que se constitui ao nível dos corpos e dos dias. O exame que coloca os indivíduos num campo de vigilância situa-os igualmente numa rede de anotações escritas; compromete-os em toda uma quantidade de documentos que os captam e os fixam. Os procedimentos de exame são acompanhados imediatamente de um sistema de registro intenso e de acumulação documentária. Um "poder de escrita" é constituído como uma peça essencial nas engrenagens da disciplina.

O indivíduo é sem dúvida uma representação "ideológica" da sociedade; mas é também uma realidade fabricada por essa tecnologia específica de poder que se chama a "disciplina". Temos que deixar de descrever sempre os efeitos de poder em termos negativos: ele "exclui", "reprime", "recalca", “censura", “abstrai”, "máscara", "esconde". Na verdade, o poder produz; ele produz realidade; produz campos de objetos e rituais da verdade. O indivíduo e o conhecimento que dele se pode ter se originam nessa produção.

FOUCAULT, Michel. Vigiar e Punir: história da violência nas prisões. Petrópolis, Editora Vozes, ed.38, 2010.

\section{Referências}

BELTRÃO, Ierecê Rego. Corpos dóceis, mentes vazias, corações frios. Didática: o discurso científico do disciplinamento. São Paulo: Imaginário, 2000.

DALBOSCO, C. A. Pragmatismo, teoria crítica e educação: ação pedagógica como mediação de significados. Campinas, SP: Autores Associados, 2010.

DELEUZE, Gilles. Um retrato de Foucault. In: conversações, 1992.

DREYFUS, Hubert L.; RABINOW, Paul. Michel Foucault: uma trajetória Filosófica. Para além do estruturalismo e da hermenêutica. Rio de Janeiro: Forense Universitária, 1995.

HELLER, Agnes. O Cotidiano e a História.4.ed. São Paulo: Paz e Terra, 1992. 
FAVACHO, André. A docência como experiência ética: aproximações entre os estudos foucaultianos e a prática docente. Disponível em:

https://revistahorizontes.usf.edu.br/horizontes/article/view/764.Acesso em 05/05/2020

FERRARI, Anderson. A modernidade como nossa herança educacional. Instrumento: revista de estudo e pesquisa em educação/Universidade Federal de Juiz de Fora, Colégio de Aplicação João XXIII. v. 5, n. 1, Juiz de Fora, p. 11-27, 2003.

FOUCAULT, Michel. A ética do cuidado de si como prática da liberdade. In: Ditos e escritos V. 2.ed. Rio de Janeiro: Forense, 2006. p. 264-287.

2002.

Em defesa da sociedade. Trad. Maria Ermantina Galvão. São Paulo, Martins fontes,

Verdade e subjectividade. In: Revista de Comunicação e linguagem. Lisboa: ed. 19,

1993.

Vigiar e Punir: nascimento da prisão. Petrópolis: Vozes, ed.40, 2014.

GALLO, Silvio. Cuidar de si e cuidar do outro. In W. O. Kohan, \& J. Gondra. Foucault 80 anos (pp.177-190). Belo Horizonte: Autêntica, 2006.

Filosofia: experiência do pensamento. São Paulo: Scipione, 2015.

Para enfrentar os desafios de ensinar filosofia na educação média brasileira. - In.

RODRIGO, Lídia Maria. Filosofia em sala de aula: teoria e prática para o ensino médio. Campinas, SP: Autores associados, 2009.

PAGNI, P. A. O cuidado de si em Foucault e as suas possibilidades na educação: algumas considerações. In L. A. Souza, T. T. Sabatine, \& B. R. Magalhães (Orgs.). Michel Foucault: sexualidade, corpo e direito. (pp. 19-46). Marília: Oficina Universitária; São Paulo: Cultura Acadêmica, 2011.

RODRIGO, Lídia Maria. Filosofia em sala de aula: teoria e prática para o ensino médio. Campinas, SP: Autores associados, 2009.

SEVERINO, Antonio Joaquim. A Importância do Ler e do Escrever no Ensino Superior. In: CASTANHO, Sérgio; CASTANHO, Maria Eugênia. Temas e Textos em Metodologia do Ensino Superior. Campinas/SP: Papirus, 2001.

SENELLART, Michel. Situação dos cursos. In: FOUCAULT, M. Segurança, território, população. $1^{\text {a }}$ ed. São Paulo: Martins Fontes, 2008.

Revista Interinstitucional Artes de Educar. Rio de Janeiro, V.7, N.2 - pág. 1148-1166 mai-ago de 2021: "Dossiê História das Mulheres e Educação" - DOI: 10.12957/riae.2021.63458 